\title{
O PROJETO DE CÓDIGO COMERCIAL E O PRINCÍPIO ENQUANTO NORMA JURÍDICA NA TEORIA PURA DO DIREITO: A (IN)SEGURANÇA JURÍDICA
}

THE DRAFT COMMERCIAL CODE AND THE PRINCIPLE AS A LEGAL STANDARD IN THE PURE THEORY OF LAW: (IN) LEGAL SE-

CURITY

\section{Marcelo Barbaresco ${ }^{1}$}

ISSUE DOI: $10.21207 / 1983.4225 .440$

\section{RESUMO}

O objeto deste artigo consiste na abordagem, sob a ótica e premissas da Teoria Pura do Direito de Kelsen, da inclusão em projeto de lei que se encontra em discussão no Congresso Nacional, de determinados princípios

\footnotetext{
${ }^{1}$ Mestrando na Universidade Presbiteriana Mackenzie; Graduado pela PUC/SP, Pós-graduado em Direito Empresarial, em Direito do Mercado Financeiro, em Direito Processual Civil, em Direito do Consumidor e em Direito Imobiliárior. Professor do Curso de Pós-Graduação lato sensu em Direito Imobiliário da FGV/SP. Professor Visitante na Faculdade Baiana de Direito e na Universidade SECOVI.
} 
relacionados ao direito empresarial enquanto norma jurídica (o Novo Código Comercial). O fundamento de sua inclusão, se afirma, é a busca da superação da insegurança jurídica no ambiente empresarial nacional e, desta forma, resgatando, a previsibilidade e a certeza de forma a reconstituir um ambiente favorável ao desenvolvimento da economia e contidos na Constituição do Brasil ${ }^{2}$.

Palavras-chave: Código Comercial. Hans Kelsen. Princípios. Norma Jurídica. Segurança Jurídica.

\section{INTRODUÇÃO}

O relator do projeto de lei que tem por finalidade a aprovação de um novo Código Comercial, Fabio Ulhoa Coelho, em conjunto com o parlamentar que propôs a iniciativa legislativa, resumiram em entrevista ao jornal Folha de São Paulo, aquilo que eles entendem como sendo o fundamento do novo diploma: (...) modernização e racionalização da legislação empresarial; melhora do ambiente de negócios; aumento da segurança jurídica e da previsibilidade das decisões judiciais; e simplificação das exigências burocráticas relativas às sociedades e aos empresários ${ }^{3}$ (g.n.).

No conjunto destes fatores, assume significância para os fins pretendidos a figura da Segurança Jurídica aliada à previsibilidade das decisões judiciais como elementos fundamentais que a nova codificação teria por finalidade resguardar ou, dito de outra forma, recompor no e para o ordenamento jurídico empresarial brasileiro, notadamente, naquilo que se refere às relações empresarialmente organizadas.

E, como forma de ancorar a concepção deste novo sistema normativo de maneira a atingir as esferas de poder de decisão do Estado e, com isto, buscar encontrar validade e eficácia social-empresarial, trabalha sob a premissa fundamental de transformar princípios jurídicos em norma

\footnotetext{
${ }^{2}$ GRAU, Eros Roberto. A Ordem Econômica na Constituição de 1988. $17^{a}$ ed. ver. e atual. São Paulo: Malheiros, 2015. A expressão Constituição do Brasil é por ele utilizada em diversas passagens da obr. cit. significando que o Brasil da atualidade dela nasceu.

${ }^{3}$ COELHO, Fábio Ulhoa; CANDIDO, Vicente. Folha de São Paulo. Caderno Tendências e Debates. Edição de 28/06/2016.
} 
jurídica ${ }^{4}$. Isto, pois, como forma de assegurar um melhor funcionamento do sistema e, por via de consequência, conferir maior previsibilidade das e nas decisões.

Vincando um pouco melhor o conceito ideológico que se entende como presente no projeto de lei: não se pode admitir situações de "imprevisibilidade imprevisível", ou seja, de hipóteses que a própria norma jurídica não admite como sendo previsível em face de determinada realidade sócio-empresarial.

E, exatamente sob este prisma que se pretende observar o projeto normativo tendo, portanto, por base o olhar e as premissas da Teoria Pura do Direito de forma a buscar os eventuais elementos de identificação da metodologia encampada pelo projeto normativo com aqueles pressupostos adotados e insculpidos pela teoria Kelseniana como forma de conferir Segurança Jurídica da e nas relações disciplinadas pelo direito.

\section{OS PRINCÍPIOS EMPRESARIAIS ENQUANTO BASE DO PROJETO NORMATIVO}

Como forma de buscar uma base para a interpretação e aplicação dos centenas de artigos previstos no projeto de Novo Código Comercial, são dedicados, dentre outros mas, especialmente após a descrição dos elementos que caracterizarão os destinatários do Novo Código Comercial, quatro artigos e através dos quais se busca estabelecer um caminho normativo principiológico para a leitura e apreensão das proposições contidas nas normas jurídicas que se seguem aos mesmos.

Dizem alguns que a metodologia legislativa adotada mantém relação com aquela consagrada através do Código de Defesa do Consumidor

\footnotetext{
${ }^{4}$ Neste sentido, também ratificam Rocha e Casquet: "O projeto de novo Código Comercial propõe a introdução de codificação que se pretende principiológica, tendo por justificativa não apenas o regramento de princípios próprios do Direito Comercial, de modo que sejam afastadas as tentativas forçadas de se invocar princípios atinentes a matérias adjacentes como Direito Civil e Direito do Consumidor, mas também com base no argumento de perpetuação de determinados conceitos já solidificados sobre a matéria". (ROCHA, Paulo Frank Coelho da; CASQUET, Andréia Cristina Bezerra. O projeto do Novo Código Comercial e as atuais tendências do Direito Comercial. Revista de Direito Empresarial, vol. 3, Mai /2014, p. 61).
} 
que, nas palavras de Nunes, "é um sistema próprio, que tem autonomia em relação às demais normas" ". Melhor esclarecendo: o Código de Defesa do Consumidor estabelece "normas gerais principiológicas (...)"6 como forma de fazer prevalecer a preponderância dos princípios; princípios estes estabelecidos através da própria norma jurídica que disciplina as relações que se sujeitam à sua observância e, neste sentido, "que se irradiam pelo próprio texto nos diversos capítulos e seções (...)"7 .

A exata conceituação do que se pode e se deve compreender como sendo um princípio de forma que se possa seguir no caminho a que se propôs este artigo é algo elementar.

Um princípio constitui um fundamento lógico de validade; um comando de justiça; um valor reconhecido; uma garantia de existência e de existir, enfim, algo que transcende e que por consequência reflete sua luz às situações que de alguma forma com ela conversar ou interagir, por necessidade ou por conveniência de justiça e de tratamento paritário.

Princípios são, pois, diz Reale: "verdades ou juízos fundamentais, que servem de alicerce ou garantia de certeza a um conjunto de juízos, ordenados em um sistema de conceitos relativos a da porção da realidade". 8 Também coloca que "toda forma de conhecimento filosófico ou científico implica a existência de princípios, isto é, de certos enunciados lógicos admitidos como condição ou base de validade das demais asserções". 9

De maneira bastante semelhante, coloca Silva: "princípios são ordenações que se irradiam e imantam os sistemas de normas (...) são núcleos de condensações nos quais confluem valores e bens $(. . .)^{10}$.

$\mathrm{E}, \mathrm{Grau}$, fazendo menção à Dworkin, que estabelece uma distinção entre objetivos concretos e que devem ser alçados, tais como o relacionado a algum aspecto econômico, político ou social (ainda que negativos e os nomina de diretrizes), arremata dizendo em seu contexto que se deve entender como sendo um princípio "as pautas que devem ser observadas

${ }^{5}$ NUNES, Rizzato. Comentários ao Código de Defesa do Consumidor. $2^{\mathrm{a}}$. ed. refor. São Paulo: Saraiva, 2005, p. 79.

${ }^{6}$ Op. Cit. p. 82.

${ }^{7}$ Op. Cit. p. 83.

${ }^{8}$ REALE, Miguel. Filosofia do Direito. 11. ed. São Paulo: Saraiva, 1986, p. 60.

${ }^{9}$ REALE, Miguel. Lições Preliminares de Direito. 17a . ed. rev. e atual. São Paulo: Saraiva, 1990, p. 299.

${ }^{10}$ SILVA, José Afonso da. Curso de Direito Constitucional Positivo. 27 ${ }^{\mathrm{a}}$. ed. rev. e atual.São Paulo: Malheiros, 2006, p. 92. 
não porque viabilizem determinadas situações econômicas, políticas ou sociais (...) mas, sim, porque sua observância corresponde a um imperativo de justiça, de honestidade ou de outra dimensão da moral"11.

De todo conveniente acrescentar o que entende Coelho acerca, especificamente, dos princípios aplicáveis ao direito comercial, uma vez que ele é o Relator do Novo Código Comercial. Neste sentido, coloca:

Cada ramo do direito tem, neste sentido, sua "ideologia", isto é, um conjunto de valores que visa prestigiar, por meio de normas constitucionais, legais ou regulamentares. São normas de âmbito muito largo, que se costumam chamar de princípios. Os princípios de uma disciplina jurídica formam sua ideologia. Nenhuma ideologia existe por si mesma. (...) Os valores que compõem a "ideologia" do direito comercial correm, hoje, o risco de desaparecerem, no emaranhado da complexa sociedade contemporânea. Se não insistirmos que a proteção jurídica feita ao investimento aproveita não apenas o investidor, em seus interesses individuais, mas principalmente à sociedade como um todo, aos poucos perder-se-á, no espírito dos juízes e outros membros da comunidade jurídica, os valores de que depende o direito comercial para sobreviver (g.n.) $)^{12}$.

Desta forma e, no campo do projeto do Novo Código Comercial, princípios relacionados ao direito empresarial, entendido este como sendo o direito aplicável às empresas enquanto atividade econômica organi$\mathrm{zada}^{13}$, são transformados em normas jurídicas e são divididos em gerais

${ }^{11}$ Op. Cit. p. 153. Neste sentido e, para a exata compreensão do sentido conferido por Dworkin, importante registrar o Grau prossegue dizendo, nos seguintes termos: "Assim - segundo Dworkin - a pauta de acordo com a qual deve ser reduzido o número de acidentes de automóvel é uma diretriz e a pauta que estipula que a ninguém aproveita sua própria fraude (torpeza) é um princípio".

${ }^{12}$ COELHO, Fábio Ulhoa. Princípios do Direito Comercial. Grupo de Estudos Preparatórios para o Congresso de Direito Comercial, 2011, p. 6. Disponível em http://www.congressodireitocomercial.org.br/2011/images/stories/pdfs/gep2.pdf. ${ }^{13}$ Neste sentido, os artigos $1^{\circ}$. e $2^{\circ}$. do projeto de lei do novo código comercial op, cit. -, que assim estabelece: "Art. $1^{\circ}$. Este Código disciplina, no âmbito do 
informadores e, de outro lado, quase que acessoriamente, princípios que destes últimos decorrem.

E, aliado a estes e, como forma de arrematar o sistema normativo jurídico principiológico, se estabelece uma outra norma-princípio através da qual se afasta a aplicação de qualquer outro que tenha por finalidade elidir a aplicação de qualquer norma jurídica prevista no sistema codificado comercialista.

É possível inferir, portanto, a busca da criação de um sistema fechado; quase que inviolável; praticamente impenetrável por quaisquer outros ramos das ciências jurídicas; tudo como forma de se justificar e, o quanto possível, petrificar a preservação da assim denominada ideologia do direito comercial.

Compreendido, desta forma, o alcance e a essência de um princípio e, de outro lado, em colaboração à esta sensibilidade, aqueles que são considerados como sendo os fundantes de uma determinada ordem jurídica, se torna conveniente conceituar o que se entende por norma jurídica e qual sua finalidade, de forma que se possa enfrentar as consequências de uma norma jurídica principiológica em contraponto à Segurança Jurídica.

Como se pode conceituar uma norma jurídica? Diz Kelsen ao estabelecer a distinção entre uma "proposição jurídica"14 e uma "norma jurídica" que esta última não é um juízo de valor, isto é, "enunciados sobre um objeto dado ao conhecimento. Elas são antes, de acordo com o seu sentido, mandamentos e, como tais, comandos, imperativos. Mas não apenas comandos, pois também são permissões e atribuições de poder ou competência" ${ }^{\prime 15}$.

Para Kelsen a norma jurídica não possui como finalidade ensinar nada a ninguém e, tampouco, estabelecer instruções de como as pessoas devem se comportar mas, apenas, "prescrever, permitir, conferir poder ou

direito privado, a organização e a exploração da empresa. Art. $2^{\circ}$. Empresa é a atividade econômica organizada para a produção ou circulação de bens ou serviços".

${ }^{14}$ Segundo Kelsen, Op. Cit. p. 80, "proposições jurídicas" são juízos hipotéticos que enunciam ou traduzem que, de conformidade com o sentido de uma ordem jurídica - nacional ou internacional - dada ao conhecimento jurídico, sob certas condições ou pressupostos fixados por esse ordenamento, devem intervir certas consequências pelo mesmo ordenamento determinadas". Dito de outra forma, uma "proposição jurídica" encerra a aplicação do Direito ao caso concreto.

${ }^{15}$ Op. Cit. p. 81. 
competência"16. E a norma jurídica, enquanto norma abstrata é que constitui o objeto da ciência jurídica, ou seja, "a ciência jurídica tem por missão conhecer - de fora, por assim dizer - o Direito e descrevê-lo com base no seu conhecimento"17.

Vale referendar que, para Kelsen, a noção de norma jurídica carrega em si a noção de "Dever Ser" e não de "Ser" e, neste sentido, Tércio Sampaio Ferraz Junior ao prefaciar a obra "Para entender Kelsen", assim coloca como forma de exemplificar a distinção entre tais categorias: "A consciência humana, diz ele, vê as coisas como elas são (a mesa é redonda) ou como ela deve ser (a mesa deve ser redonda). Normas, nestes termos, são prescrições de dever ser"18.

Compreendido, portanto, na visão kelseniana o alcance e o sentido de uma norma jurídica e que pode albergar um princípio, transformando-o, por consequência, em norma jurídica, os princípios gerais informadores que assumem no projeto de Novo Código Civil a posição de normas jurídicas são os seguintes: o da Liberdade de iniciativa; o da Liberdade de competição e o da Função social da empresa.

E, em decorrência dessas normas jurídicas gerais e informadoras, surgem como consequência outras normas jurídicas principiológicas explicativas que têm por finalidade vincar, por conta da normatização do princípio da liberdade de iniciativa, que outros princípios são reconhecidos enquanto norma jurídica, quais sejam: o da imprescindibilidade, no sistema capitalista, da empresa privada para o atendimento das necessidades de cada um e de todos; o do lucro obtido com a exploração regular e lícita de empresa como o principal fator de motivação da iniciativa privada; o da importância, para toda a sociedade, da proteção jurídica liberada ao investimento privado feito com vistas ao fornecimento de produtos e serviços, na criação, consolidação ou ampliação de mercados consumidores e desenvolvimento econômico do país; o da empresa privada como importante pólo gerador de postos de trabalho e tributos, bem como fomentador de riqueza local, regional, nacional e global ${ }^{19}$.

\footnotetext{
${ }^{16}$ Op. Cit. p. 81.

${ }^{17}$ Kelsen, Op. Cit. p. 81.

${ }^{18}$ COELHO, Fábio Ulhoa. Para Entender Kelsen. 5a . ed. São Paulo: Saraiva, 2009 , p. XVI.

${ }^{19}$ Neste sentido, o artigo $5^{\circ}$. do projeto do Novo Código Comercial.
} 
De outro lado, é alçada à condição de norma jurídica no âmbito no projeto do Novo Código Comercial e, por conta da conjugação dos princípios da liberdade de iniciativa e de competição, o princípio segundo o qual é proibida a concorrência desleal, bem como aquelas condutas entendidas como sendo parasitárias ${ }^{20} 21$.

No mesmo sentido, há norma jurídica na esfera deste novo código que explicita e detalha o que deve ser entendido como sendo o princípio da função social da empresa e quando o mesmo deve ser compreendido como atendido.

Portanto, normatiza que a empresa cumpre sua função social ao gerar empregos, tributos e riqueza, ao contribuir para o desenvolvimento econômico, social e cultural da comunidade em que atua, de sua região ou do país, ao adotar práticas empresariais sustentáveis visando à proteção do meio ambiente e ao respeitar os direitos dos consumidores, desde que com estrita obediência às leis a que se encontra sujeita ${ }^{22}$.

Perceptível, portanto, que com a adoção do princípio enquanto norma jurídica o que se pode cogitar, especialmente, quando se presume que o racional deste Novo Código Comercial é assumir e, para tanto, copilar a metodologia adotada pelo Código de Defesa do Consumidor ${ }^{23}$, é que

${ }^{20}$ Uma conduta pode ser entendida como sendo parasitária quando, uma empresa não concorrente, se utiliza de maneira indevida, do trabalho, do reconhecimento, do sucesso de uma outra empresa, de um produto, de uma marca distintiva ou de características dessas, para fins de obter vantagem a que não possui direito. Dito de outra forma, a empresa dita "parasita" replica fórmula de sucesso de outra com a finalidade de buscar obter vantagem ilícita.

${ }^{21} \mathrm{O}$ artigo $6^{\circ}$. do projeto do Novo Código Comercial assim estabelece esta principiologia normativa.

${ }^{22}$ Neste sentido, o artigo $7^{\circ}$. do projeto do Novo Código Comercial.

${ }^{23}$ Se realiza esta inferência por conta, também, do conteúdo do artigo subscrito por Ives Gandra da Silva Martins e Fabio Ulhoa Coelho e publicado no Caderno Opinião do "O Estado de São Paulo", Edição de 22/06/2016, em que colocam após discorrerem acerca da necessidade de se aprimorar um Código de 1850 às novas realidades constitucionais: "Leia-se, por exemplo, o artigo 4. ${ }^{\circ}$, parágrafo único, do Substitutivo Paes Landim: "Decorre dos princípios da liberdade de iniciativa empresarial e da liberdade de concorrência o reconhecimento: (a) da imprescindibilidade, no sistema capitalista, da empresa privada para o atendimento das necessidades de cada um e de todos; (b) do lucro obtido com a exploração regular da empresa como o principal fator de motivação da iniciativa privada; (c) da impor- 
questões porventura relacionadas à crítica que se faz ao denominado ativismo judicial estão sendo compreendidas e enfrentadas em sua essência estrutural a partir da codificação.

E, acerca do ativismo judicial e, especialmente, na esfera constitucional, coloca Prado, fazendo menção ao entendimento de Lênio Luiz Streck:

(...) o exercício da função transformadora da norma não conhece limites: "Não só porque as cortes constitucionais estão situadas fora e acima da tradicional tripartição dos poderes estatais, mas também porque a sua atividade interpretativa se desenvolve, essencialmente, em torno de enunciados abertos, indeterminados e plurissignificativos - as fórmulas lapidares que integram a parte dogmática das constituições. Em razão dessas constatações, muitos doutrinadores afirmam que estamos vivendo um período de ativismo judicial, "onde a nova magistratura estaria disposta a resgatar as promessas de emancipação social inseridas na Constituição de 1988", numa efetiva "transferência do poder político do legislador para o juiz ${ }^{24}$.

tância, para toda a sociedade, da proteção jurídica assegurada ao investimento privado (...)". À medida que a lei incorpore esses conceitos (verdadeira explicitação da Constituição), isso os torna objeto de conhecimento obrigatório dos estudantes, estudiosos e profissionais do Direito. Os programas das faculdades vão incluir o seu estudo; as listas de pontos dos concursos da magistratura e do Ministério Público deverão necessariamente contemplá-los; produzir-se-ão estudos, artigos, dissertações e teses sobre o dispositivo; etc. Com isso, os valores veiculados pela norma legal serão conhecidos e incorporados por mais pessoas.

Esta estratégia de reafirmação de valores não é nenhuma novidade no Brasil. Foi graças ao reconhecimento, na lei, da "vulnerabilidade do consumidor", constante do artigo $4 .^{\circ}$, I, do CDC, que este importantíssimo fundamento valorativo de toda a proteção especial dos consumidores passou a frequentar os argumentos jurídicos de doutrinas, petições, sentenças e acórdãos."

${ }^{24}$ PRADO, Izabel Cristina Navarro. Interpretação conforme a Constituição. In Direito e Poder Econômico no Mercado. BARBARESCO, Marcelo; BUENO, Neide. (orgs). Curitiba: CRV, p. 126-7. E, acerca de STRECK, PRADO remete o 
Melhor dizendo, na medida em que alguns entendem que o poder judiciário pode estar exorbitando de suas funções tendentes à aplicação da norma jurídica na medida em que, ao realizar a aplicação de princípios variados estão constituindo "entendimentos" não contemplados dentre aqueles possíveis e previsíveis pela norma jurídica, se pretende esculpir e incluir, no sistema das normas jurídicas, quais seriam os princípios que, também ao serem transformados em normas jurídicas, deveriam ser os únicos a serem observados e aplicados de forma a se consagrar a Segurança Jurídica e, portanto, a previsibilidade do previsível.

Neste sentido, ao se assim proceder, o que se pretende defender é o afastamento, por conta de sua efetiva invalidade, da aplicação de qualquer outro principio que não esteja contemplado através da própria norma jurídica que estabelece quais seriam aqueles que fundam e fundamentam o sistema de direito comercial (ou, mas modernamente, chamado de empresarial). Portanto, qualquer situação não contemplada pela norma jurídica principiológica tenderia a restar afastada do campo de aplicação de um direito "fechado" e que circunscreveu seus limites, inclusive através da disciplina restrita dos norteadores informadores de sua própria significação.

E, neste cenário positivista restrito, restaria afastada, por consequência lógica e imediata, a insegurança jurídica decorrente daquele fato inesperado e imprevisível com relação àquele que não assumiu o risco pois estas exorbitantes das possibilidades previsíveis.

Assim, quando uma norma jurídica determina uma sanção a um específico comportamento, este será considerado um delito e, por via de consequência, o seu oposto, será considerado um dever jurídico. E exatamente neste sentido que se pode refletir e concluir acerca da motivação do Novo Código Comercial ao inserir princípios como normas jurídicas.

Dito de uma outra maneira, qual seja, em havendo a transformação de princípios que, segundo Kelsen, constituíram apenas fontes informadoras da aplicação do Direito mas, não, elementos integrantes da norma jurídica e, portanto, entendidos como algo externo ao estudo da Ciência Jurídica, sua inserção no universo do dever-ser tenderia a trazer ao sistema jurídico maior Segurança Jurídica, exatamente pela circunstância de se transformar em norma jurídica.

leitor para Hermenêutica jurídica e $(m)$ crise. Porto Alegre: Livraria do advogado. Ed., 2000, p. 44-5. 
E o que seria, então, a Segurança Jurídica? Como de alguma forma mencionado anteriormente, seria a possibilidade da certeza da previsibilidade daquilo previsto ou previsível normativamente. Que seja avaliado este elemento e, com mínima maior profundidade, no ponto seguinte.

\section{A PURA APLICAÇÃO DA TEORIA PURA DO DIREITO NOS PRINCÍPIOS ENQUANTO NORMA E A SEGURANÇA JURÍDICA}

A possibilidade da certeza da previsibilidade do previsto normativamente, se encontra amparada e consolidada quando se avalia a essência da Teoria Pura ${ }^{25}$ do Direito que, segundo Mascaro, se trata da maior obra de Kelsen e que "expõe os pressupostos mais importantes de sua visão jusfilosófica", bem como localiza seu pensamento como sendo juspositivista estrito $^{26}$.

Para tanto, se torna conveniente recordar alguns de seus elementos estruturais de forma que se torne possível, ao final, uma avaliação crítica acerca de sua aplicabilidade àquilo que, aparentemente, se pretende com o estabelecimento de princípios de direito empresarial enquanto norma jurídica, ou seja, conferir Segurança Jurídica através do estabelecimento de princípios enquanto norma.

Para a depuração tendente ao encontro da "pureza" e definição de um objeto próprio de estudo Kelsen se vale da forma e, não do conteúdo do Direito, para a definição do objeto da Ciência Jurídica ${ }^{27}$.

\footnotetext{
${ }^{25}$ E se diz que é "pura" pois não trata dos dados concretos da realidade jurídica, ou seja, trata apenas da avaliação do dever-ser e, não, do ser. E Kelsen, Op. Cit. p. 1, assim coloca: “(...) isto significa que ela se propõe garantir um conhecimento apenas dirigido ao Direito e excluir deste conhecimento tudo quanto não pertença ao seu objeto, tudo quanto não se possa, rigorosamente, determinar como Direito. ${ }^{26}$ MASCARO, Alysson Leandro. Filosofia do Direito. 5 ${ }^{\text {a }}$ ed. ver., atual. e ampl. São Paulo: Altas, 2016, p. 338 e 340.

${ }^{27} \mathrm{Na}$ Op. Cit. p. 79 é assim colocado: "Na afirmação evidente de que o objeto da ciência jurídica é o Direito, está contida a afirmação - menos evidente - de que são as normas jurídicas o objeto da ciência jurídica, e a conduta humana so o é na medida em que é determinada nas normas jurídicas como pressuposto ou consequência, ou - por outras palavras - na medida em que constitui conteúdo de normas jurídicas".
} 
Neste sentido, para ele, o objeto de estudo constitui apenas e tão somente a compreensão e os significados da norma jurídica, devendo ser afastados quaisquer outros elementos enquanto necessário for este distanciamento para a definição de seu exato limite. Ratifica Coelho ao da mesma forma assim colocar: "(...) excluídos do âmbito de interesse do cientista jurídico os fatores especificamente sociais, econômicos, culturais, morais ou políticos interferentes na produção da norma e também os valores prestigiados em sua edição" 28 .

Trata-se, portanto, de uma opção metodológica de forma a conformar e delimitar, perfeitamente, o objeto do estudo que se empreenderá e, não, afastar do campo do conhecimento e do entendimento do mundo da vida outras circunstâncias que, se sabe, influenciam ou até de certa forma, conduzem para construção do próprio Direito e, por via reflexa, por vezes, culminam com o nascimento de uma norma jurídica geral ou individual ${ }^{29}$.

Apenas se afasta, se retira, do campo da ciência jurídica elementos estranhos à própria norma jurídica, mas - repita-se - que não são desconhecidos do criador da criatura denominada Teoria Pura do Direito; muito pelo contrário.

Para seu criador, a norma jurídica decorre de um processo pensado, discutido e de alguma maneira conformado pela tolerância e pelo governo da maioria democrática. Coloca Kelsen: "Quando a Teoria Pura empreende delimitar o conhecimento do Direito em face destas disciplinas ${ }^{30}$, fá-lo não por ignorar ou, muito menos, por negar essa conexão, mas porque intenta evitar um sincretismo metodológico que obscurece a essência da ciência jurídica (...)"31

É reconhecido, portanto, que o Direito é multifacetário e que interage com diversos saberes e com a ativa vida social em regime de uma

\footnotetext{
${ }^{28}$ Op. Cit. p. 49.

${ }^{29}$ Parafraseando Kelsen, como o objeto da Ciência Jurídica se limita ao estudo das normas jurídicas e a forma como as mesmas foram concebidas e, portanto, seu papel se limita a descrever o Direito, não pode ela criar normas gerais ou individuais, uma vez que este papel é atribuível à autoridade jurídica, entendida esta como aquela que possui o poder de aplicar o direito ou, então, de concebê-lo.

${ }^{30}$ Se refere às seguintes disciplinas: psicologia, sociologia, ética e a teoria política, em Op. Cit. p. 1.

${ }^{31}$ Op. Cit. p. 1-2.
} 
sociedade plural. Mas não seria, o Direito, como informado, o objeto de estudo da Ciência Jurídica ${ }^{32}$.

O objeto de estudo é conformado e restrito ao estudo da maneira através da qual a norma jurídica foi concebida formalmente, bem de seus intrínsecos limites interpretativos, afastando-se, por via de consequência lógica, da avaliação da justiça ou da injustiça de um determinado comando legal. Em síntese: apenas, se adota sua metodologia e, normativa, para avaliar se determinado comando é válido ou inválido e quais seriam seus limites.

Neste sentido, emblemática a colocação de Kelsen nos seguintes termos:

O Direito a aplicar forma, em todas estas hipóteses, uma moldura dentro da qual existem várias possibilidades de aplicação, pelo que é conforme ao Direito todo ato que se mantenha dentro deste quadro ou moldura, que preencha esta moldura em qualquer sentido possível ${ }^{33}$.

O conjunto de todos estes elementos têm por finalidade se criar uma ciência que, como tal, possua os requisitos de independência que, por via de consequência, se torne aplicável, autonomamente, à avaliação de toda e qualquer norma jurídica e em qualquer sistema de Direito, ou seja,

\footnotetext{
${ }^{32}$ Neste sentido, coloca Mascaro - Op. Cit. p. 340 -:’Para Kelsen, são coisas distintas o direito e a ciência do direito. Tal separação das duas esferas de apreciação sobre o direito é fundamental para o entendimento da teoria kelseniana. Na prática, o direito se mistura a todos os demais fenômenos sociais. Há juízes que julgam de acordo com suas inclinações sociais e políticas, operadores do direito que procedem a macetes nos autos processuais, testemunhas que faltam com a verdade, juristas corruptos. Tudo isso está no mundo dos fatos. Nem por isso, cientificamente, o direito será considerado a partir da política, ou como logro, ou como mentira ou como atividade corrupta. A ciência do direito paira em outro patamar. Ela trata de explicar por que o juiz pode julgar, por que há tais regras do processo, por que tal pessoa é considerada, formalmente, uma testemunha em um processo". E mais à frente, na mesma Op. Cit. p. 342, arremata ao dizer: “(...) Kelsen não apregoa, como o vulgo imagina, que o direito seja puro,, somente normativo. Pelo contrário, o direito é contraditório, haurido imediatamente das contradições sociais e se seus operadores".

${ }^{33}$ Op. Cit. p. 390.
} 
universalmente, parafraseando, de forma sintetizada, a colocação de Mascaro $^{34}$.

Estabelece Kelsen que "a Teoria Pura do Direito é uma teoria do direito positivo - do Direito positivo em geral, não de uma ordem jurídica especial. É teoria geral do Direito, não interpretação de particulares normas jurídicas, nacionais ou internacionais". E um pouco mais à frente, conclui: "É Ciência Jurídica e não política do Direito". ${ }^{35} \mathrm{E}$, assim se manifesta Coelho, ao examinar o elemento "pureza" de Kelsen: "A pureza da ciência do direito, portanto, decorre da estrita definição de seu objeto (corte epistemológico) e de sua neutralidade axiológica)." 36

Em face destes elementos recordados da Teoria Pura do Direito, se entende como sendo possível, doravante, realizar uma abordagem acerca da inserção de determinados princípios de direito comercial enquanto norma jurídica na visão da teoria kelseniana, como forma de se resgatar uma desejável Segurança Jurídica ao ambiente que constitui objeto de regulação pelo Novo Código Comercial.

A inserção pretendida pelo Novo Código Comercial no sentido de trasladar princípios em normas jurídicas busca, de certa maneira, conferir à norma posta a independência metodológica normativa da Ciência Jurídica concebida por Kelsen. Tanto assim que, Coelho, ao comentar a Teoria Pura, assim descreve a função do cientista do direito: "deve-se ocupar exclusivamente da norma posta. Os fatores interferentes na produção da norma, bem como os valores que nela se encerram são rigorosamente estranhos ao objeto da ciência jurídica" ${ }^{37}$.

Portanto, se pode inferir que uma das principais razões relacionadas a este traslado se refere exatamente à situação descrita pela Ciência do Direito kelseniana, como forma de se apartar da avaliação quando da conversão da norma jurídica em norma jurídica individual, quaisquer outros elementos estranhos à própria moldura interpretativa e que com ela se relaciona e se aperfeiçoa através do estabelecimento dos princípios enquanto norma jurídica objeto de estudo do dever-ser. Ou seja, para aquele

\footnotetext{
${ }^{34}$ Op. Cit. p. 346. E coloca que: "O conteúdo das normas varia em cada qual desses Estados, mas a lógica formal das normas não".

${ }^{35}$ Op. Cit. p. 1.

${ }^{36}$ Op. Cit. p. 3.

${ }^{37}$ Op. Cit. p. 2.
} 
sistema, apenas se aplicam aquelas normas jurídicas e aqueles princípios transformados em normas.

E a natureza desta norma jurídica principiológia seria a de uma norma não-autônoma ${ }^{38}$ na classificação e entendimento de Kelsen uma vez que: (i) se encontrará ligada à outra norma jurídica que estabelecerá a sanção a ser aplicada por conta de sua não observância, ou seja, estará ela "essencialmente ligada à segunda; ela apenas estabelece - negativamente - o pressuposto a que a segunda liga a sanção" ${ }^{39}$ e, (ii) pelo simples fato dela apenas servir como uma norma que determina "com maior exatidão o sentido de outras normas, definindo porventura um conceito utilizado na formulação de uma outra norma ou interpretando autenticamente uma norma"40.

De outro lado, na medida em que os princípios são transformados em norma jurídica, cabe indagar acerca das situações de normalidade e previsibilidade que sua aplicação ensejará, ou seja, ao serem aplicadas as normas jurídicas principiológicas serão elas capazes de afastar a insegurança jurídica ocasionada pela ausência de previsibilidade quando da subsunção de um fato a uma norma? Esta a reflexão que se deve empreender.

Ao realizar a aplicação da norma jurídica ao caso em concreto, se desenvolve uma interpretação autêntica, entendida esta, nas palavras de Kelsen, como sendo a "(...) interpretação de uma norma pelo órgão jurídico que a tem de aplicar (...)" e, desta forma, “(...) não somente se realiza uma das possibilidades reveladas pela interpretação cognoscitiva (obtida por uma operação de conhecimento) da mesma norma, como também se pode produzir uma norma que se situe completamente fora da moldura que a norma a aplicar representa" ${ }^{41}$.

\footnotetext{
${ }^{38}$ Para Kelsen, a norma primária não seria aquela através da qual se estabelece a prescrição mas, sim, aquela que estabelece a sanção. Portanto, Kelsen coloca - Op. Cit. p. 64 - que: (...) uma ordem jurídica, (...), pode, no entanto, ser caracterizada como ordem de coação, na medida em que todas as suas normas que não estatuam elas próprias um ato coercitivo e, por isso, não contenham um prescrição mas antes confiram competência para a produção de normas ou contenham uma permissão positiva, são normas não autônomas, pois apenas têm validade em ligação com uma norma estatuidora de um ato de coerção".

${ }^{39}$ Op. Cit. p. 61.

${ }^{40}$ Op. Cit. p. 64.

${ }^{41}$ Op. Cit. p. 394.
} 
Em face deste cenário, conveniente a ponderação acerca da (in)segurança jurídica que se traduz na conversão de um princípio em uma norma jurídica. Isto, pois, se de um lado se toma como correto afirmar que ao assim proceder se estará emoldurando o sistema do direito comercial empresarial de forma que nele sejam aplicáveis apenas aqueles primados segundo os quais constituem sua razão fundante, de outro, poderá se traduzir em um elemento de inquietação em face do intrínseco e natural subjetivismo da norma principiológica.

Se, de um lado, se pode atestar e aferir um ganho com a consolidação e reafirmação de postulados inerentes a uma determinada ciência ou sistema de forma a afastar a aplicação de quaisquer outros que não estejam especificados em uma norma, de outro, por conta da ideologia principiológica, se poderia inferir que a certeza ou calculabilidade, restariam, em certa medida, comprometidas, não obstante o cerco cerrado pela moldura, corresponder, de maneira natural, a uma maior segurança, comparativamente, ao sistema aberto que contemporaneamente, se vivencia.

$\mathrm{Na}$ atualidade e, por conta da inexistência desta consolidação dos princípios informadores do sistema normativo relacionado ao direito comercial empresarial, em algumas situações são desenvolvidos e aplicados entendimentos lastreados em princípios tais e quais que não mantém relação com a essência do funcionamento do sistema empresarial, ou seja, se distanciam de forma impar de suas finalidade constitucional.

E, por conta desta impetuosa dilaceração de um sistema e que culmina com a eliminação da razão existencial de um regime jurídico que visa o incentivo e o desenvolvimento da economia nacional e, por via de consequência, a superação da rotineira situação de nossos cidadãos, é que se pode entender como produtiva esta tentativa legislativa. 
Produtiva, pois visa assegurar a defesa da positividade ${ }^{42}$, não obstante a existência de certas críticas ${ }^{43}$. Diz-se positividade pois, nos últimos tempos, repise-se, se percebe a cada momento, o crescimento do denominado ativismo judicial que, como se sabe, decide cada vez mais tendo por base os chamados princípios do direito, mesmo que afrontando a norma jurídica.

Neste sentido, de todo interessante transcrever o que coloca Grau acerca da calculabilidade e confiança no sistema jurídico e sua correlação com o sistema capitalista mencionando, para tanto, Max Weber em Economia y Sociedade, obra datada de 1969 - de forma que se verifique a sempre atualidade do tema - :

A propósito, tenho lembrado Weber, para quem as exigências de calculabilidade e confiança no funcionamento da ordem jurídica e na chamada Administração constituem exigência vital do capitalismo racional; o capitalismo industrial depende

\begin{abstract}
${ }^{42}$ Acerca deste tema, Grau - Op. Cit. p. 19 - e ao discorrer acerca da justiça e o direito como forma de se resolver as questões relacionadas à contradição entre o universal e cada situação particularmente considerada, coloca: "A única tentativa viável, embora precária, de mediação entre ambas é encontrada na legalidade e no procedimento legal, ou seja, no direito posto pelo Estado, este com o qual operamos no cotidiano forense, chamando-o direito moderno, identificado à lei". E pouco mais adiante segue dizendo que "Essa busca nos coloca sob o risco da substituição da racionalidade formal do direito (com sacrifício da legalidade e do procedimento legal) por uma racionalidade de conteúdo construída a partir da ética (qual ética?!), à margem do direito". Portanto, a reflexão acerca do possível abandono da positividade pode representar uma inversão ou até mesmo, uma redistribuição disfarçada entre os poderes de uma república e, com isto e, por conta disso, acabar por ferir de morte O Estado de Direito que, como se sabe, consagra e assegura os direitos essenciais e os que dele decorrem de forma direta e indireta.

${ }^{43}$ Neste sentido - ROCHA, Paulo Frank Coelho da; CASQUET, Andréia Cristina Bezerra. O projeto do Novo Código Comercial e as atuais tendências do Direito Comercial. Revista de Direito Empresarial, vol. 3/2014, Mai /2014, p. 61 que assim coloca: "A respeito da disciplina, parece louvável a tentativa de articular determinados princípios como verdadeiros pilares sobre os quais os demais dispositivos devem se firmar; no entanto, além de ser dispensável repetir aqueles já previstos na Carga Magna de 1988, parece não haver consonância entre o propósito de tecer regramentos gerais, por meio de princípios, e detalhar tantos assuntos que deveriam ser disciplinados pelas partes, se e quando necessários”.
\end{abstract}


da possibilidade de previsões seguras - deve poder contar com estabilidade, segurança e objetividade no funcionamento da ordem jurídica e no caráter racional e em princípio previsível das leis e da Administração. Trata-se, então, da ordem pública, constituídas pelas normas jurídicas (...): os agentes econômicos, no interior de um mercado extremamente complexo no qual o ganho voltado à acumulação de capital joga papel preponderante, necessitam de uma justiça e de uma Administração cujo funcionamento possa ser, em princípio, calculado racionalmente. Essa possibilidade corresponde a uma exigência inafastável do mercado. (...) Pois saber com certo grau de certeza que os contratos serão respeitados, isso dizia Franz Neumann - é indispensável ao sucesso empresarial $^{44}$.

Desta forma, como se verifica um crescimento das decisões lastreadas na aplicação e interpretação de princípios, se objetiva, pelo menos, circunscrever quais seriam eles os aplicáveis, em essência, a um determinado sistema jurídico normativo como forma de se resgatar o grau de certeza minimamente desejável para o avançar de uma economia capitalista competitiva e de mercado.

Mas, acerca do governo dos princípios em detrimento do das normas jurídicas, Grau realiza uma afirmação que deve servir de norte para uma reflexão acerca deste tema, diz ele: "O fato é que não se interpreta a norma: a norma é o resultado da interpretação". ${ }^{45}$

Em face desta circunstância e através da qual normas são criadas por conta da interpretação, se deve refletir acerca da efetividade de princípios serem transformados em normas jurídicas, ou seja, ao serem positivados, se teria por, naturalmente, expandido o campo de interpretação e, portanto, como diz Kelsen, da moldura de uma norma que poderá tender ao infinito.

\footnotetext{
${ }^{44}$ GRAU, Eros Roberto. Por que Tenho Medo dos Juízes (a interpretação/aplicação do direito e os princípios. $7^{\mathrm{a}}$. ed. refundida do ensaio e discurso sobre a interpretação/aplicação do direito. São Paulo: Malheiros, 2016, p. 16.

${ }^{45}$ Op. Cit. p. 18.
} 
Neste cenário e, por conta do ideal subjetivo de um princípio, se poderia estar chancelando, mais uma vez, o largo campo da interpretação e, por via de consequência, normatizando elementos de incerteza.

Mais uma vez, se traz as palavras de Grau ao discorrer acerca da aplicação dos princípios pelo poder judiciário mas, agora, ele mesmo fazendo menção à Kelsen, quando este último se refere aos princípios enquanto fundamento de uma decisão no sentido de recusar qualquer importância a eles; diz ele:

(...) Nenhum deles pode fundamentar a validade da decisão judicial. Somente uma norma geral positiva poderá fazê-lo. Os princípios morais, políticos ou dos costumes podem ser chamados de jurídicos apenas na medida em que influenciam a criação de normas jurídicas individuais pelas autoridades competentes. Não obstante, não se confundem com as normas jurídicas cujos conteúdos a eles sejam adequados. E o fato de que sejam chamados princípios jurídicos não significa - como o nome parece dizer - sejam princípios do direito." ${ }^{46}$

Parece que a posição de Grau, ao se respaldar em Kelsen, deva ser contemporizada de forma a se afastar entendimentos que possam conduzir a interpretações que de alguma forma tornem questionáveis entendimentos consolidados acerca de uma determinada situação jurídica.

Isto pois e, repetindo as palavras de Kelsen, "também se pode produzir uma norma que se situe completamente fora da moldura que a norma a aplicar representa" ${ }^{47}$. Se reconhece, portanto, a validade de uma interpretação autêntica neste sentido, tanto que assim coloca Kelsen: "É fato bem conhecido que, pela via de uma interpretação autêntica (...), é muitas vezes criado direito novo - especialmente, pelos tribunais de última instância". ${ }^{48}$

Por conta deste conjunto de informações e das possibilidades que uma norma principiológica poderá traduzir quando inserida em um contexto normativo, cabe razoavelmente e, para que se possa concluir, avaliar

\footnotetext{
${ }^{46}$ Op. Cit. p. 105.

${ }^{47}$ Op. Cit. p. 394.

${ }^{48}$ Op. Cit. p. 395.
} 
suas consequências sob a ótica da Segurança Jurídica necessária ao empreendedorismo capitalista.

Mais uma vez, parafraseando Kelsen, um Estado é uma ordem jurídica e, enquanto ordem jurídica, é um Estado de Direito que, por sua vez, corresponde e satisfaz aos atributos da democracia e da segurança jurídica. E, portanto, "Estado de Direito (...) é uma ordem jurídica (...) segundo a qual a jurisdição e a administração estão vinculadas às leis..."

De certa maneira complementando ou ainda melhor detalhando o conceito de Kelsen acerca do Estado de Direito, Lima, fazendo menção à Canotilho, coloca que ele se desenvolve no entorno de dois conceitos fundamentais, quais sejam, o da estabilidade e o da previsibilidade e, neste sentido explica e detalha que (a) quanto à estabilidade significa dizer que as decisões “(...) não devem poder ser arbitrariamente modificadas, sendo apenas razoável a alteração das mesmas quando ocorram pressupostos materiais particularmente relevantes" e, doutro lado e, naquilo que se refere à previsibilidade, afirma que (b) refere-se à “(...) exigência de certeza e calculabilidade, por parte dos cidadãos, em relação aos efeitos jurídicos dos actos normativos". 50

Se percebe, por conta da detida apreciação das colocações de cada um daqueles cujas idéias foram transcritas neste capítulo que dois conceitos são reiteradamente repetidos, quais sejam, o da calculabilidade e o da previsibilidade. Desta forma, cabe o retorno ao pensamento crítico acerca da norma jurídica principiológica e como ela poderá se subsumir à tais conceitos que, como dito, constituem a base, a moldura daquilo que se intitula Segurança Jurídica.

Universos de segurança total-ideal, certamente, por mais desejosos que possam ser em uma sociedade capitalista estruturalmente orientada para a produção e circulação de massas, dificilmente poderão ser concebidos, especialmente em face de uma ciência social e humana como é a do direito.

${ }^{49}$ Op. Cit. p. 346

${ }^{50}$ LIMA, Daniela de. Segurança Jurídica na teoria pura do direito de Hans Kelsen. Disponível em http://www.egov.ufsc.br/portal/conteudo/seguran\%C3\%A7a-jur\%C3\%ADdica-na-teoria-pura-do-direito-de-hans-kelsen.

Portal de e-governo, inclusão digital e sociedade do conhecimento. Acesso em 11/10/2016. 
Mas, de outro, iniciativas como a do projeto de lei que tenciona, circunscrever em um quadro composto por normas jurídicas, as possíveis possibilidades de um sistema com sua própria ideologia, se não conseguir afastar a insegurança jurídica, pelo menos propiciará uma maior inviolabilidade quanto à previsibilidade das possibilidades possíveis.

Neste sentido, acerca das palavras e suas significações no mundo da vida e que, por vezes, representam o que não são ou se tornam ilusões do que seriam e, portanto, se relacionando com a interpretação da norma jurídica e a consequente (in)segurança, as palavras de Saramago são fundamentais neste processo, quando assim coloca: “(...) parece que não vês que as palavras são títulos que se pegam às cousas, não são as cousas, nunca saberás como são as cousas, nem sequer que nomes são na realidade os seus, por que os nomes que lhes deste não são mais do que isso, o nome que lhes deste (...)",51.

\section{CONCLUSÃO}

As lições da ciência de Kelsen em sua Teoria Pura do Direito continua a permear e a irradiar seus conceitos na atualidade; mesmo que seja de alguma forma ou medida negada ou afastada sua utilização e efetividade para os fins a que se propõe alguns na atualidade. Há, certamente, alguma mitigação mas, não, seu esquecimento.

$\mathrm{O}$ isolamento da norma jurídica enquanto objeto de estudo exclusivo e, como tal, enquanto essência da Ciência Jurídica como forma de afastar, emblematicamente, do saber qualquer outro fato que não seja a norma e forma, transformou aquilo que se entendia como impuro e incerto, naquilo que tornou-se puro e certo. E, portanto, de aplicação universal, independentemente, de seu conteúdo e circunstâncias externas à norma positivada.

E, calcado na pureza e na certeza, enriquece e enaltece a Segurança Jurídica tão hoje ameaçada ou, então, talvez tão enfraquecida por conta da realização de um estudo não purificado das normas que dele fazem parte. Devendo-se, por inverídica, se afastar qualquer afirmação no sentido

${ }^{51}$ SARAMAGO, José. As Intermitências da Morte. 17ª Reimpressão. São Paulo: Companhia das Letras: 2016, p. 72. Sendo certo, talvez que, tal colocação tenha sua base filosófica em Wittgenstein. 
de que se desconhece ou que se deva desconhecer a realidade do mundo da vida no qual se situa e se compreende a norma jurídica e o Direito. Mas, sobretudo e acima de tudo, honrando aquilo que representa, em um Estado de Direito, sua base e alicerce mediato: suas leis. Dignificação Democrática e que funda um Estado.

O projeto do Novo Código Comercial, mesmo que se diga não ser de base teórica kelseniama, busca resgatar a certeza, a calculabilidade e a previsibilidade tão fundamentais ao desenvolvimento do sistema capitalista. Resgate este que, como se procurou demonstar pode ser que, sim, possua um certo lastro na Teoria Pura do Direito. Dogmática esta que dignifica, de certa maneira, a situação da Segurança Jurídica, hoje tão maculada por conta de uma insegurança materialmente visível.

Portanto, mesmo que um princípio, elástico em sua essência, venha a ser transformado em norma jurídica e que, uma vez estudado e avaliado enquanto norma, venha a se tornar representação das possibilidades possíveis enquanto moldura que resguarda em seu interior os entendimentos factíveis, tanto melhor assim o será para a Segurança Jurídica e para o desenvolvimento do mercado empresarial nacional. O cenário previsível é o que se espera e deseja. Contra a total imprevisibilidade, a previbilidade, mesmo que sintética ou plástica é aquilo que melhor pode representar para o desenvolvimento de uma empresarialidade racionalmente orientada ao resultado certeiro de uma atividade econômica incerta.

Por fim e, apenas para deixar consignado, como forma de afastar eventual entendimento equivocado no sentido de se afirmar que Coelho é kelseniano, ele mesmo afirma, em obra de sua autoria que: "É imprescindível que se registre, desde logo, que não sou kelseniano"52.

\section{REFERENCIAS BIBLIOGRÁFICAS}

BRASIL. Código Comercial. Projeto de Lei 1572/2011. Disponível em http://www.camara.gov.br/proposicoesWeb/prop_mostrarintegra; jsessionid=F7C11DDD731FD3EC8541D53C89BBB314.proposi

\footnotetext{
${ }^{52}$ Op. Cit. p. XI, Prefácio. E à p. 70, coloca: “O empreendimento da teoria pura do direito é um fracasso. (...) Sem Kelsen, sem a teoria pura, sem o desafio kelseniano, talvez a filosofia jurídica não estivesse ainda pronta para a exploração dessas novas e revolucionárias possibilidades."
} 
coesWeb2 ?codteor $=888462 \&$ filename $=$ Tramitacao -

PL+1572/2011. Acesso em 11/10/2016.

COELHO, Fábio Ulhoa. Para Entender Kelsen. 5a ed. São Paulo: Saraiva, 2009, p. XVI.

. Folha de São Paulo. Caderno Tendências e Debates. Edição de 28/06/2016, Disponível em: http://www1.folha.uol.com.br/opiniao/2016/06/1785613-codigocomercial-construcao-democratica.shtml. Acesso em 11/10/2016. Princípios do Direito Comercial. Grupo de Estudos Preparatórios para o Congresso de Direito Comercial, 2011, p. 6. Disponível em http://www.congressodireitocomercial.org.br/2011/images/stories/p dfs/gep2.pdf. Acesso em 11/10/2016.

GRAU, Eros Roberto. A Ordem Econômica na Constituição de 1988. $17^{\mathrm{a}}$ ed. ver. e atual. São Paulo: Malheiros, 2015.

. Por que Tenho Medo dos Juízes (a interpretação/aplicação do direito e os princípios. $7^{\mathrm{a}}$. ed. refundida do ensaio e discurso sobre a interpretação/aplicação do direito. São Paulo: Malheiros, 2016.

KELSEN, Hans. Teoria Pura do Direito. Trad. João Baptista Machado. $8^{\text {a }}$. ed. São Paulo: Martins Fontes, 2009.

LIMA, Daniela de. Segurança Jurídica na teoria pura do direito de Hans Kelsen.

Disponível em http://www.egov.ufsc.br/portal/conteudo/seguran\%C3\%A7ajur\%C3\%ADdica-na-teoria-pura-do-direito-de-hans-kelsen.

Portal de e-governo, inclusão digital e sociedade do conhecimento. Acesso em 11/10/2016.

MARTINS, Ives Gandra da Silva; COELHO, Fábio Ulhoa. A Importância do Código Comercial: Códigos não são importantes apenas para fins jurídicos; têm também relevante função cultural. O Estado de São Paulo. Caderno Opinião. Edição de 22/06/2016. Disponível em http://opiniao.estadao.com.br/noticias/geral,a-importancia-docodigo-comercial,10000058530. Acesso em 11/10/2016.

MASCARO, Alysson Leandro. Filosofia do Direito. $5^{\text {a }}$. ed. ver., atual. e ampl. São Paulo: Altas, 2016.

NUNES, Rizzato. Comentários ao Código de Defesa do Consumidor. $2^{a}$. ed. refor. São Paulo: Saraiva, 2005.

PRADO, Izabel Cristina Navarro. Interpretação conforme a Constituição. In Direito e Poder Econômico no Mercado. BARBARESCO, Marcelo; BUENO, Neide. (orgs). Curitiba: CRV, p. 126-7. 
REALE, Miguel. Filosofia do Direito. 11. ed. São Paulo: Saraiva, 1986. . Lições Preliminares de Direito. $17^{\text {a }}$. ed. rev. e atual. São Paulo: Saraiva, 1990.

ROCHA, Paulo Frank Coelho da; CASQUET, Andréia Cristina Bezerra. O projeto do Novo Código Comercial e as atuais tendências do Direito Comercial. Revista de Direito Empresarial, vol. 3, Mai/2014.

SARAMAGO, José. As Intermitências da Morte. $17^{\text {a }}$. Reimpressão. São Paulo: Companhia das Letras: 2016.

SILVA, José Afonso da. Curso de Direito Constitucional Positivo. $27^{\mathrm{a}}$. ed. rev. e atual. São Paulo: Malheiros, 2006. 